\title{
THE DEPOSED CHILD
}

\author{
BY \\ RICHARD MEYER, M.B., M.R.C.P. \\ (From the Public Health Department, Metropolitan Borough of St. Pancras)
}

This article is a survey of the alleged habits of 156 children before and after the birth of a new sibling.

\section{Material}

Mothers were questioned who had two or more children of whom the youngest was less than a year old. These women were attending five welfare centres in the Metropolitan Borough of St. Pancras. From the returns of birth notifications and of first attendances it is estimated that about 80 per cent. of the mothers in this area who have a baby less than a year old attend a centre. It therefore seems reasonable to consider these mothers as representative of the district, remembering, however, that they do not include those who are rich enough to go elsewhere, or those who are too busy or too careless to attend anywhere. Most of the mothers were attending with a new baby, and not because of the ex-baby about whom questions were asked. Eighty-five per cent. of their husbands were artisans or labourers, and 15 per cent. were clerks or highly skilled technicians; 94 per cent. were British. Of the children, 102 (Group A) were under five years old, and 54 (Group B) were between five and fourteen years old.

\section{Method}

Consecutive mothers were questioned by the writer. Half of these attended his own clinic and the rest were waiting at the four other clinics. Five mothers were excluded during the survey. Two of these could not speak English, and a third had a cleft palate. Another had a deaf and dumb child. The fifth had three children of whom the middle one had died.

The name, age, and sex of the baby, the sex of the adjacent child and its age when the baby was born, and the number of siblings were noted. The mother was told the nature of the survey and she was asked whether the ex-baby had shown any signs of jealousy, and, if so, the time of onset and duration. Specific questions were asked regarding previous and present appetite, micturition and bowel habit; and if the child had ever hit the baby. As a rough guide to general behaviour she was asked if he stuttered, blinked, bit his nails, or sucked his thumb, and if, when annoyed, he hit his mother or ' kept it to himself.'

The father's profession and approximate length of military service were noted. The mother was asked how the child had been prepared for the new baby, and why, in her opinion, some children seemed jealous and others not. Any other comments of interest (e.g., behaviour of older siblings) were noted.

If the mother stated that her child had shown unmitigated pleasure at the arrival of the baby she was congratulated. Otherwise she was reassured that many children are disturbed at this time. The tone of questioning was not that of a cross-examination, and therefore no resentment was encountered by the writer or the health visitors.

\section{Preparation}

In group $\mathrm{A}$ (children under five years) 33 per cent. had been told that a baby was to be bought, and some of them had saved up for this purpose. To 27 per cent. nothing had been told at all; of these, three-quarters were under two years old. The explanation to 26 per cent. had been that a new child would be sent or fetched. This explanation was usually vague, but in one case a nurse, and in another a father, was mentioned as the donor. The facts had been told to 10 per cent. No word was heard of storks, gooseberry bushes, or doctors, though three parents had given analogies using dolls, an apple tree, and seeds respectively.

In group $B$ (children over five years) buying persisted as the major simile; 20 per cent. were presumed to have guessed or known; and 8 per cent. had been told the truth by a parent. One mother said that babies came from China, and another that they were like flowers.

In group $A$, which is large enough for subdivision, there was no definite correlation between the words used and the subsequent behaviour of the child. One felt that it was not so much what the mothers said as the way in which they said it that mattered. It is, however, disappointing that such a large proportion of the older children are either told nothing or else a story which must puzzle any child who is not blind.

\section{Ordinary Behaviour}

Many children had inconvenient habits which were unrelated to the arrival of the new baby. These provide a group standard for later changes. Some of these habits were evenly distributed between 
those children who later showed jealousy of the baby and those who did not.

Aggression. Before the birth of the baby 23 per cent. of the children in group $A$, and 12 per cent. in group B, were said to hit their mothers when annoyed. Some of the mothers who were never attacked thought that their children ' did not want to ' and others that they ' did not dare to' hit them. In our dealings with children it is not easy to distinguish between these two types of meekness.

Appetite. Of group A, 13 per cent. and of group B, 7 per cent. had always eaten poorly. (The children in group B were at school for most of the day and therefore less under maternal observation.)

Stuttering. Of group A, 12 per cent. stuttered; none did so in Group B. Transient stammering is quite common in pre-school years.

Bowel habit. In group A, 7 per cent. had ' always been constipated '; 2 per cent. had dvowed fear of the lavatory; and 1 per cent. had faecal incontinence following measles. In group B, 3 per cent. had chronic constipation.

Nailbiting and Nailpicking. These habits had existed for a long time in 7 per cent. of group A and 14 per cent. of group $B$.

Blinking. Eyelid tics existed in 6 per cent. of group $A$ and 2 per cent. of group $B$.

Two habits occurred with different frequency among those children who later showed jealousy of the baby and those who did not.

Bed-wetting. At the time of enquiry 29 per cent. of group A and 4 per cent. of group B wet their beds. If those children are excluded who had recommenced enuresis after a marked period of control (i.e. those who began again after illness, the baby's arrival, or some clearly dramatic event), there remain twenty-three children who had never gained sphincter control, fourteen of these being over two and a half years of age at the time of enquiry. Nine of these latter fourteen were among the children who later showed no jealousy of the baby. Furthermore, the five children who were still enuretic after the age of four years were all among those who were 'not jealous' of the baby when this arrived.

Thumbsucking. At the time of enquiry 19 per cent. of group A and 6 per cent. of group $B$ were said to suck their thumbs. Excluding those who had recommenced this habit only after an illness or the baby's birth, there remain twenty-two children who had always sucked their thumbs. Fourteen of these were among the children who later showed open signs of jealousy of the baby, and only eight of the twenty-two were among those who did not.

The figures for enuresis and thumbsucking are small for subdivision, but they hint that early sphincter control, the thumbsucking habit, and a tendency to show resentment of a new sibling may be associated. The possible significance of this will be discussed at the end of the survey.

\section{General Change in Behaviour}

In a survey of this nature it is difficult to know how far to rely on the statements of a mother. A high proportion of truthful answers about enuresis, for example, may be expected if the survey is conducted with tact and a sense of humour. But the word jealousy is tinged with varying shades of significance.

'Jealousy.' In group A, 51 per cent. and in group B 28 per cent. were said to have shown signs of jealousy.

In group A, 3 per cent. and in group B, 2 per cent. had been taken to physicians because of the unpleasant change in their behaviour when the new baby came.

Some of these mothers merely realized that the child regarded the baby with mixed feelings, among which resentment was apparent. Other women chose to interpret the behaviour of the child as resentful, for they saw the toddler's jealousy more as a compliment than an inconvenience, and blew strongly on any spark of it which could be found.

'Absence' of jealousy. In group A, 49 per cent. and in group $B, 72$ per cent. were described as not being jealous of the baby. In 10 per cent. of group A and 4 per cent. of group B there seemed to the writer to be doubt about this description. Two blatant examples are given.

EXAMPLE 1. Baby L. was ten weeks old. Dora, aged one year and three months, was said to have been not at all jealous. She had, however, been off her food for six weeks, constipated for two weeks, and, although previously a placid child, had now commenced to hit her mother when she was annoyed.

EXAMPLE 2. Mrs. J. was questioned when her baby was ten weeks old. Lucy, aged four years, had shown nothing but pleasure since the baby arrived. Mrs. J. was surprised at this, for Lucy had previously objected strongly if her mother took strange babies on her lap. Four weeks later Mrs. J. asked for another interview. She said that for the last fortnight Lucy had been a terror, climbing into her mother's bed at night and saying, 'I won't love baby if you scold me.' This behaviour had begun when she had been sent off to a nursery school with the remark, ' I'll be able to see to baby now without you messing about the place.'

In 39 per cent. of group $A$ and 68 per cent. of group $B$ the mothers gave fair reason for their statement that the child was 'not jealous' of the baby. Examples are given because some. writers have questioned whether any child would feel indifferent or predominantly glad to have a new sibling.

EXAMPle 3. Mrs. Y.: 'I expect she's got so used to her baby cousins round the place that one more baby doesn't seem to make any difference.'

EXAMPle 4. Mrs. P.: ' He was so jealous of my husband when he was demobbed that he is glad to have baby as something for himself to look after. Maybe he spent all his jealousy on his father.' 
EXAmple 5. Mrs. R.: 'I've an invalid husband and there is never any time to fuss either the girl or the baby.'

ExAmple 6. Mrs. O'C.: 'I told Joe (aged three years nine months) that we were going to get a baby off the apple tree. He was in the room when I was in labour and he did not like that so he ran out. But he soon came back. I thought that he would be jealous, specially as it was twins and as he had been alone with me till his dad came home last year. But apart from perhaps crying a little more he has not minded a bit. . . . Of course he has always hit me occasionally. ... . But he goes out to play and when he comes in he pops over to look at the babies and is almost fatherly. I suppose it is because he is of an independent nature and because I like bringing up kids.'

Most emotions are hybrid. The purpose of this section has been to indicate in general terms how much children vary in their behaviour after a particular crisis.

\section{Specific Changes in Habit}

Aggression. In group A, 26 per cent. and in group B, 6 per cent. hit, pinched, bit, or pulled the hair of the baby. This was often a source of anxiety to the parents.

In group $A, 11$ per cent. who had previously been docile began to hit their mothers after the baby arrived. One child was said to have begun hitting a beloved grandmother with whom he had stayed during his brother's birth.

Appetite. In group A, 21 per cent. had anorexia after the new baby came. This usually began immediately, but was occasionally delayed until the baby was brought to the table for meals. It most often lasted a few weeks, but the variations were between three days and nine months or more. There was loss of appetite through incidental illnesses (e.g. after measles) in 4 per cent. Three per cent. ate much better after the baby arrived. In group B 7 per cent. lost their appetite when the baby was born, and 4 per cent. had eaten much better since then.

Loss of appetite in these children was almost always accompanied by other signs suggestive of resentment. On the rare occasions when this was not so, it is possible that the new baby was just a pleasant distraction, of greater interest than food. One does not know whether the children whose appetite increased were altogether more happy, or if they were merely easier during meals now that the maternal eye was fixed on the baby.

Bowel habit. In group A, 3 per cent. had been constipated for a few weeks shortly after the baby's birth. Two per cent. refused to be taken to the lavatory except during the baby's feeds, 1 per cent. had diarrhoea associated with much aggressive behaviour when the baby was a few weeks old. In group B, no change in bowel habit was reported.
Bed-wetting. In group A, 5 per cent. had recommenced enuresis or wet their beds much more frequently since the advent of the baby. One girl, aged two years nine months, said frankly that she did not see why she should not copy the baby. In group $B, 2$ per cent. recommenced bed-wetting after the baby was born.

Thumbsucking and nailbiting. In group A, 5 per cent. had begun thumbsucking or grossly exaggerated this habit since the baby's birth; 2 per cent. had begun nailbiting and nailpicking. In group B, 1 per cent. had adopted a finger-mouth habit when the baby came.

Blinking and stuttering. There seemed no association between the onset of these habits, when present, and the arrival of the baby.

\section{Influence of Sex}

The sex of the baby and that of the adjacent child have no influence on the early relations of the two as seen in this survey. When group $\mathbf{A}$ and group $\mathbf{B}$ are subdivided into the pairs MM, MF, FM, and FF, these arrangements are approximately the same among the 'jealous' and ' non-jealous' children.

\section{Influence of Age}

The influence of age is shown in table 1 and in the figure. The curve of increasing emotional maturity is not smooth. In this it resembles Gesell's description (1941) of the development of neuromuscular co-ordination in children. Overt jealousy has its peak of incidence in the third year, which is also notorious for difficulties in speech and in movement. It should also be noted that no child is too young or too old to behave with great inconvenience to himself and his parents if he thinks that he has been displaced. Three examples are given because of their age.

TABLE 1

INFLUENCE OF AGE

\begin{tabular}{c|c|c|c}
\hline $\begin{array}{c}\text { Age in } \\
\text { years }\end{array}$ & $\begin{array}{c}\text { No. } \\
\text { jealous }\end{array}$ & $\begin{array}{c}\text { No. } \\
\text { not jealous }\end{array}$ & Group \\
\hline $0-1 \frac{1}{2}$ & 8 & 6 & \\
\hline $1 \frac{1}{2}-2$ & 11 & 10 & A \\
\hline $2-3$ & 15 & 8 & \\
\hline $3-4$ & 10 & 16 & \\
\hline $4-5$ & 8 & 10 & B \\
\hline $5-6$ & 3 & 9 & \\
\hline $6-7$ & 3 & 7 & \\
\hline $7-10$ & 7 & 16 & \\
\hline $10-14$ & 2 & 7 & \\
\hline
\end{tabular}




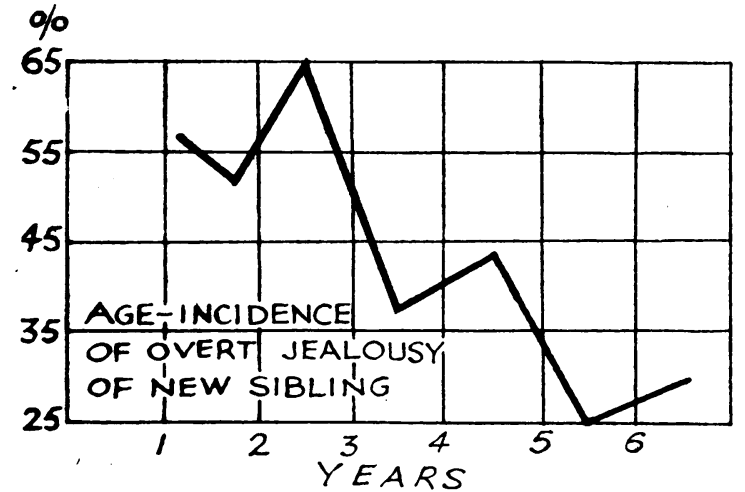

FIG. 1-Influence of age.

EXAMPLe 7. ' Roddy (aged ten months) did not like baby from the first. $\mathrm{He}$ is puzzled at my breast feeding, and he is always awake now (aged thirteen months) when I go in to give baby the ten o'clock feed. He asks for tea then. He hits baby and me often. When baby is taken up he hides his face in his hands.'

EXAMPLE 8. Winston, aged fifteen months when his baby brother was born, stayed with his grandmother for two weeks at that time. His mother said: 'He used to be good, but since his return he won't play with his nice toys. He waits till I begin to breast-feed baby, and then he bangs tins and bottles together. He screams at night now, and he gets terrified of things like caterpillars and the fur collar of my coat. My milk is going, he worries me so much. But he kisses baby a lot and doesn't hurt him.'

EXAMPLE 9. ' Ronald (aged fourteen years) said that if the new baby was a boy he would throw it out of the window and if it was a girl he would gas it. He has done neither but I am not happy about him and baby.'

\section{Influence of Family Size}

Table 2 shows the number of families of different sizes in the survey. This shows no evidence in

TABLE 2

INFLUENCE OF FAMILY SIZE

\begin{tabular}{|c|c|c|c|c|}
\hline \multirow{2}{*}{$\begin{array}{l}\text { No. of } \\
\text { children }\end{array}$} & \multicolumn{2}{|c|}{ Group A } & \multicolumn{2}{|c|}{ Group B } \\
\hline & 'Jealous' & $\begin{array}{c}\text { 'Not } \\
\text { jealous }\end{array}$ & 'Jealous' & $\begin{array}{l}\text { 'Not } \\
\text { jealous }\end{array}$ \\
\hline 2 & 32 & 30 & 7 & 22 \\
\hline 3 & 10 & 13 & 7 & 9 \\
\hline 4 & 4 & 4 & 1 & 3 \\
\hline $5+$ & 6 & 3 & 0 & 5 \\
\hline
\end{tabular}

support of two facile generalizations, frequently voiced, namely, that ' only' children are specially liable to resent the advent of a new sibling; and that a large family is in itself the guarantor of a spirit of 'give and take.' The early behaviour of children would appear to depend much more on who is running the family and on the particular status of each child in the family group.

\section{Prevention and Treatment of Jealousy}

All the mothers maintained that they had foreseen the possibility of the child resenting the arrival of a new baby. But, apart from the verbal announcements noted above, most had waited to see what would happen. When the baby arrived some women instinctively treated the displaced child as Stekel (1931) and other leading psychiatrists have recommended. That is, they assured him of their continued affection and encouraged him to take an active part in the care of the baby. It should be emphasized here that the spirit behind the action is very important. One mother, who gave her toddler the dregs of the baby's bottle, had not really understood his needs.

\section{Conclusions}

To look at any child through a tracing of percentages would be a bad prelude to assessment. In this survey a map of habits and changes in habit has been sketched. Against the background of this it should be possible to keep a sense of perspective when looking at a child, and to appraise him better.

The incidence of certain inconvenient habits in ' normal ' children has been indicated. The proportion of children with chronic aberrations of appetite and bowel habit is smaller than might appear from the numbers who wait in surgeries. Conversely, there are many late enuretics, and many pre-school children with tics, stammering (Edwards, 1939), and aggressive behaviour who never reach the out-patient department.

After the new baby arrives the behaviour of the deposed child is by no means uniform. One regards the baby mainly as a plaything, of rather more interest than a puppy. Another sees the new baby as a supplanter; his mind and body are greatly disturbed, and, with the thumb of one hand in his mouth, he strikes the baby with the other, resorting to infantile habits himself. A third child, after a short period of overt jealousy, seems to decide, with his mother's encouragement, that he will be independent. He patronizes the baby and begins to grow up.

What factors influence the expression of such feelings? That of age is clearly shown in the survey. But the vast influence of previous upbringing, mingled with hereditary traits, is subtle, and only hints of it emerge in a survey of this size. A 
strong clinical impression was gained that the casual though affectionate mother had the least bother with her child. That these mothers were not over-attentive, even before the new baby arrived, was suggested by the higher incidence of late sphincter control among their children (cf. Maberley, 1945). There were also fewer' thumb-suckers among the 'non-jealous' children. Now, although the significance of thumb-sucking has not been decided (Valentine, 1942), it is at least a gratifying habit to which older children resort more in times of relative loneliness (e.g. at night and with strange adults). It is possible that the bulk of the nonjealous children had been forced into selfdependence early in life and did not need the extra solace of a thumb in the mouth. In general the child of a phlegmatic mother may not be clean in his habits, but he has grown to depend on himself at an early age; and he sees little cause for anxiety when his mother nurses a new sibling.

The questionnaire method has been neglected in the study of normal children (Bühler, 1935): Its value is limited, but may be considerable in emphasizing the wide range of so-called normality.

\section{Summary}

At welfare centres in St. Pancras, London, 156 mothers of two or more children were questioned about the habits of the ex-baby. The incidence of certain inconvenient habits before and after the arrival of the new baby is noted, with special reference to those in children under the age of five years. The influence of preparation, sex, age, family-size, and previous upbringing on overt jealousy is discussed.

I wish to thank Dr. Dennis Geffen for his criticism of this paper, and the health visitors of St. Pancras for their interest in the survey.

\section{REFERENCES}

Bühler, C. (1935). Birth to Maturity. London. - pp. 215-21.

Edwards, C. (1939). Survey of Child Psychiatry. Ed. Gordon, R. G. London. p. 211.

Gesell, A. et al. (1940). First Five Years of Life. London. Maberley, A. (1945). Psychology in General Practice. Ed. Moncrieff, A. M. London. p. 110.

Stekel, W. (1931). Primer for Mothers. New York.

Valentine, C. W. (1942). Psychology of Early Childhood. London. pp. 334-6. 